\title{
Tributyltin-Induced Apoptosis Requires Glycolytic Adenosine Trisphosphate Production
}

\author{
Hélène Stridh, ${ }^{\dagger}$ E ugenio Fava, ${ }^{\ddagger}$ Barbara Single, ${ }^{\ddagger}$ Pierluigi Nicotera, ${ }^{\ddagger}$ \\ Sten Orrenius, ${ }^{\dagger}$ and Marcel Leist*, ${ }^{*}$ \\ Institute of Environmental Medicine, Division of Toxi cology, Karolinska Institutet, Box 210, \\ S-171 77 Stockholm, Sweden, and Department of Molecular Toxicology, Faculty of Biology, \\ University of Konstanz, Box X911, D-78457 Konstanz, Germany
}

Received March 10, 1999

\begin{abstract}
The toxicity of tributyltin chloride (TBT) involves $\mathrm{Ca}^{2+}$ overload, cytoskel etal damage, and mitochondrial failure leading to cell death by apoptosis or necrosis. Here, we examined whether the intracellular ATP level modulates the mode of cell death after exposure to TBT. When J urkat cells were energized by the mitochondrial substrate, pyruvate, low concentrations of TBT $(1-2 \mu \mathrm{M})$ triggered an immediate depletion of intracel lular ATP followed by necrotic death. When ATP levels were maintained by the addition of glucose, the mode of cell death was typically apoptotic. Glycolytic ATP production was required for apoptosis at two distinct steps. First, maintenance of adequate ATP levels accel erated the decrease of mitochondrial membrane potential, and the release of the intermembrane proteins adenylate kinase and cytochrome $C$ from mitochondria. A possible role of the adenine nucleotide exchanger in this first ATPdependent step is suggested by experiments performed with the specific inhibitor, bongkrekic acid. This substance delayed cytochrome c release in a manner similar to that caused by ATP depletion. Second, caspase activation foll owing cytochrome c rel ease was only observed in ATPcontaining cells. BCl-2 had only a minor effect on TBT-triggered caspase activation or cell death. We conclude that intracellular ATP concentrations control the mode of cell death in TBTtreated J urkat cells at both the mitochondrial and caspase activation levels.
\end{abstract}

\section{Introduction}

Organotin compounds, particularly tributyltin (TBT), ${ }^{1}$ have been widely used as biocides and are now recognized environmental hazards $(1,2)$. For instance, high levels of trial kylated organotin compounds have been detected in aquatic organisms as a consequence of intense use of TBT-containing antifoulant paint for ships (3-5). Several in vivo studies have shown that TBT targets the mammalian immune system, hereby causing thymic atrophy and immunosuppression (6-9). In vitro, TBT induces apoptosis of rat thymocytes or human lymphoma cells $(10,11)$

Despite its high cytotoxic potency, TBT exhibits a relatively low chemical reactivity, e.g., toward isolated protein thiols (12). A defined molecular target for TBT

\footnotetext{
* To whom correspondence should be addressed: Molecular Toxicology, University of Konstanz, Box X911, D-78457 Konstanz, Germany. Telephone: +49-7531-884054. Fax: +49-7531-884033. E-mail: marcel.leist@uni-konstanz.de.

† Karolinska Institutet.

‡ University of Konstanz.

${ }^{1}$ Abbreviations: $\Delta \Psi$, mitochondrial membrane potential; ADK, adenylate kinase; ANT, adenine nucleotide exchanger; BA, bongkrekic acid; DTT, dithiothreitol; FCCP, carbonylcyanide p-(trifluoromethoxy)phenylhydrazone; FCS, fetal calf serum; HEPES, 4-(2-hydroxyethyl)1-piperazineethanesulfonic acid; PNG medium, medium with pyruvate and no glucose; TBT, tributyltin chloride; TMRE, trimethylrhodamine ethyl ester.
}

is still unknown, although a large variety of mechanisms have been suggested to account for its cytotoxicity. One of the initial events observed after exposure to TBT seems to be an increase in the level of intracellular free $\mathrm{Ca}^{2+}$, which may be involved in triggering or aggravating mitochondrial damage, inhibition in protein synthesis, and oxygen radical production (13-16). The best characterized targets of TBT with respect to disturbance of energy metabolism are the mitochondria, whereas glycolytic enzymes have been found to be little affected (17). Inhibition of mitochondrial ATP synthesis by TBT has been suggested to occur via two different mechanisms: (i) exchange of halide for hydroxyl ions across the inner mitochondrial membrane and induction of matrix swelling (18) and (ii) binding to a component of the mitochondrial $\mathrm{F}_{0} \mathrm{~F}_{1}$-ATP synthase, producing an oligomycin-like effect (19). In J urkat cells, TBT depletes the mitochondrial membrane potential and triggers apoptosis at low concentrations, or necrosis at high concentrations (20).

However, the reasons for this switch in the mode of cell death have remained unknown. A switch from apoptosis to necrosis, or the simultaneous occurrence of both types of cell death within the same tissue, is frequently encountered in toxic or pathological lesions (for a review, see ref 21). Possibly, apoptosis and necrosis involvesimilar initial signaling steps $(22,23)$. Prevention of a default apoptotic program by oxidative (24) or 
nitrosative (25) stress, by caspase inhibitors (26), or by metabolic situations precluding caspase activation (27, 28) may then result in necrosis. One metabolic parameter that has been shown to determine the mode of cell death is the intracellular ATP concentration $(29,30)$.

TBT is a typical example of a xenobiotic mitochondrial toxin which can both trigger a cell death program and inhibit mitochondrial ATP production. Therefore, the availability of substrates for glycolytic ATP production in the cell may determine whether a given TBT concentration triggers apoptosis or necrosis. Here, we investigated whether TBT induced indeed different modes of cell death when ATP was provided by glycolysis and/or oxidative phosphorylation. In addition, we determined steps of the apoptotic program at which energy-requiring reactions are necessary for TBT-triggered apoptosis to proceed.

\section{Materials and Methods}

Cell Cultures. J urkat T cells were grown in RPMI-1640 medium supplemented with $10 \%$ fetal calf serum (FCS). Before all experiments, cells were washed and resuspended in serumfree medium without glucose containing $2 \mathrm{mM}$ pyruvate to sustain ATP synthesis by oxidative phosphorylation (PNG medium). After adaptation to this medium for $60 \mathrm{~min}$, cells were exposed to 0 or $2.5 \mu \mathrm{M}$ oligomycin for a further $45 \mathrm{~min}$ in the same medium as described previously (29) and then challenged by addition of TBT. Where indicated, PNG medium was supplemented with $10 \mathrm{mM}$ glucose.

Clones of J urkat cells (31) transfected with Bcl-2 or control vector (neo) were generously provided by S. Korsmeyer (Dana Farber Cancer Institute, Boston, MA). Expression of Bd-2 was controlled by Western blot using a monoclonal antibody (clone N-19) from Santa Cruz Biotechnology (Santa Cruz, CA). The expression level was $\geq 50$ times greater than the control. Cells such as wild-type J urkat cells were used for experiments.

Determination of the Type of Cell Death. Cultures were stained with a mixture of chromatin dyes as described previously $(29,32)$. Briefly, cells were incubated with the membrane permeant dye $\mathrm{H}-33342(500 \mathrm{ng} / \mathrm{mL})$ and the membrane impermeant dye SYTOX (500 nM) (Molecular Probes, Eugene, OR). Stained cells were examined with a fluoresence microscope (Leica DM-IRB). Necrotic cells (damaged plasma membrane and noncondensed nuclei) and apoptotic cells (condensed or fragmented nuclei) were scored.

ATP Measurements. Cells $\left(2 \times 10^{5}\right)$ were harvested and lysed with a somatic ATP-releasing reagent (Sigma, Deisenhofen, Germany). ATP concentrations in the lysates were determined in a luminometric assay using the ATP dependency of the light-emitting luciferase-catalyzed oxidation of luciferin (Boehringer Mannheim, Mannheim, Germany) (29). The values were calibrated against an ATP standard curve. The ATP content of control cells in PNG medium ( $1.6 \mathrm{nmol} / \mathrm{mg}$ of protein) was defined as $100 \%$.

Release of Mitochondrial Proteins. Cytosolic fractions from J urkat cells were isolated by a quick cell lysis method with digitonin (33). While the mixture was being vortexed, lysis buffer [9.4 $\mu \mathrm{g}$ of digitonin $/ 10^{6}$ cells and $500 \mathrm{mM}$ sucrose in PBS $(2 \mathrm{mM}$ $\mathrm{NaH}_{2} \mathrm{PO}_{4}, 16 \mathrm{mM} \mathrm{Na}_{2} \mathrm{HPO}_{4}$, and $150 \mathrm{mM} \mathrm{NaCl}$ )] was quickly added to the cell suspension ( $4 \times 10^{6}$ cells in PBS). Heavy organelles and cell debris were pelleted for $60 \mathrm{~s}$ at $14000 \mathrm{~g}$ and $4{ }^{\circ} \mathrm{C}$.

The supernatant (cytosolic fraction) was analyzed for cytochrome c by SDS-PAGE and immunoblotting (Pharmingen), or adenylate kinase (ADK) activity by spectrophotometric analysis as described by Bergmeyer (34). The concentration of $\mathrm{NADH}$ in the reaction mixture [20 $\mu \mathrm{L}$ cytosolic fraction in 100 $\mathrm{mM}$ triethanolamine ( $\mathrm{pH}$ 7.6), $10 \mathrm{mM}$ EDTA, $16 \mathrm{mM} \mathrm{MgSO}_{4}$ $150 \mathrm{mM} \mathrm{KCl}, 500 \mu \mathrm{M} \mathrm{NADH}, 1 \mathrm{mM}$ ATP, $500 \mu \mathrm{M}$ phosphoenolpyruvate, $1.5 \mathrm{mM}$ adenosine monophosphate, $5 \mu \mathrm{M}$ roten- one, $5 \mu \mathrm{M}$ oligomycin, 250 units $/ \mathrm{mL}$ pyruvate kinase, and 250 units $/ \mathrm{mL}$ lactate dehydrogenase] was monitored for $20 \mathrm{~min}$. Activity in lysates after treatment with Triton-X 100 was defined as $100 \%$.

Caspase Activity. Caspase activity was determined as the ability of cytosolic extracts to cleave the DEVD-afc (35). Cleavage by the cytosolic extracts (constant cell number, approximately $10 \mu \mathrm{g}$ of total protein) was followed in reaction buffer [50 mM HEPES, $10 \mathrm{mM}$ dithiothreitol, 1\% sucrose, and $40 \mu \mathrm{M}$ DEVD-afc (0.1\%)] over a period of $30 \mathrm{~min}$ at $37^{\circ} \mathrm{C}$ with a $\lambda_{\text {ex }}$ of $390 \mathrm{~nm}$ and $\mathrm{a} \lambda_{\mathrm{em}}$ of $505 \mathrm{~nm}$ in a microplate fluorescence reader (Bio-Tech Instruments, Winooski, VT). The activity was calibrated with afc standard solutions. For detection of procaspase-3 processing, cells were lysed after the indicated times in RIPA buffer $(150 \mathrm{mM} \mathrm{NaCl}, 50 \mathrm{mM}$ Tris, 1\% NP-40, 0.25\% sodium deoxycholate, and $1 \mathrm{mM}$ EGTA), which was supplemented with inhibitors of proteases [ $1 \mathrm{mM}$ phenylmethanesulfonyl fluoride (PMSF), $1 \mathrm{mM}$ benzamidine, $1 \mathrm{mM}$ iodoacetate, $1 \mathrm{mM}$ iodoacetamide, $40 \mu \mathrm{M}$ leupeptin, $10 \mu \mathrm{g} / \mathrm{mL}$ antipain, and $5 \mu \mathrm{g} / \mathrm{mL}$ pepstatin]. Protein was separated by SDS-PAGE (12\% gels), and el ectroblotted onto nitrocellul ose membranes (Hybond $\mathrm{ECL}$, Amersham-Buchler Corp., Braunschweig, Germany). Blots were stained with anti-caspase-3 antibodies (1:1000, generously provided by D. W. Nicholson, Merck Frost Center, Quebec City, PQ) and developed with a peroxidase-coupled secondary antibody and chemiluminescent detection with ECL (AmershamBuchler Corp.).

Mitochondrial Potential. The mitochondrial membrane potential $(\Delta \Psi)$ was measured using three independent methods $(27,28)$. (i) J urkat cells were incubated as described above, aliquots withdrawn at established time points, and cells resuspended in medium containing $5 \mathrm{nM}$ tetramethylrhodamine ethyl ester (TMRE, Molecular Probes) and analyzed by FACS (FACScalibur, Becton Dickinson, Heidelberg, Germany) using 488 $\mathrm{nm}$ excitation and $590 \mathrm{~nm}$ emission filters essentially as described previously (36). Calibration of the instrument was carried out using the LinearF low Orange kit (Molecular Probes). Data were elaborated using Cell Quest software (Becton Dickinson). (ii) We used a sensitive fluorimetric method developed initially to follow small or transient $\Delta \Psi$ or shape changes in a cell suspension over time $(28,37)$. Briefly, $7.5 \times 10^{5} \mathrm{cell} / \mathrm{s} / \mathrm{mL}$ were suspended in a fluorimeter cuvette in PNG medium without phenol red, and supplemented with $20 \mathrm{nM}$ TMRE. TMRE accumulates in mitochondria as a direct function of $\Delta \Psi$. Under these loading conditions, the high TMRE concentration reached in the mitochondria causes fluorescence quenching. Reduction of $\Delta \Psi$ leads to the loss of TMRE from mitochondria and consequently unquenching, which is reflected by an increase in the overall fluorescence ( $\left.\lambda_{\mathrm{ex}}=568 \mathrm{~nm}, \lambda_{\mathrm{em}} \geq 590 \mathrm{~nm}\right)$. In contrast, hyperpolarization enhances mitochondrial accumulation of TMRE and causes further fluorescence quenching. For up to $3 \mathrm{~h}$, control cells did not display a loss of $\Delta \Psi$ or decreased viability. The mitochondrial uncoupler FCCP $(5 \mu \mathrm{M})$ was used at the end of each experiment to determine the polarization/ depolarization state of the mitochondria. All experiments were performed at least three times, and representative traces are shown. (iii) Aliquots of cells were stained with 5 nM TMRE and positioned on a coverslip-bottomed cell culture dish. The images were obtained using a confocal mi croscope (Leica TCS 4D, Leica, Heidel berg, Germany) with the same instrument settings for each experiment and fluorescence filters as described for the unquenching method. Cells exhibiting either a normal (high fluorescence) or low (FCCP-like; low fluorescence) membrane potential were then imaged (28). Each experiment was repeated at least 10 times, and representative images were selected.

Cytochrome c Staining. The cytochrome c distribution was examined by immunocytochemistry (33). Briefly, J urkat cells were prelabeled for $60 \mathrm{~min}$ with the mitochondria-specific al dehyde-fixable dye Mitotracker Red ( $20 \mathrm{nM}$, M ol ecular Probes) before treatment with TBT. At different time points after the treatment, cells were fixed in paraformaldehyde (4\%), washed twice in PBS, and permeabilized in PBS, supplemented with 
$0.1 \%$ Triton $\mathrm{X}-100$ for $10 \mathrm{~min}$. An anti-cytochrome c antibody (clone 6H2.B4, Pharmingen, Hamburg, Germany) was used as the primary antibody and an Alexa 488-conjugated (M olecular Probes) secondary antibody for detection purposes. The dye $\mathrm{H}-33342$ was used as nuclear counterstain. Images of the stained cells were obtained using a confocal microscope (Leica TCS 4D).

\section{Results}

Effects of TBT on the Intracellular ATP Level in J urkat Cells. Low TBT concentrations $(1-2 \mu \mathrm{M})$ trigger apoptosis in J urkat cells within $1-2 \mathrm{~h}$ in complete cell culture medium (20). We first examined how TBT modified intracellular ATP levels under different metabolic conditions. Using different incubation media containing either glucose and the ATP synthase inhibitor oligomycin, or pyruvate and glucose, or pyruvate alone (PNG medium), it was possibleto select conditions where ATP was generated by glycolysis, by glycolysis and oxidative phosphorylation, or by oxidative phosphorylation alone. The ATP level of unstimulated cells was not significantly different under the different culture conditions (29). However, after exposure to TBT $(2 \mu \mathrm{M})$, cells incubated in the absence of glucose lost $\geq 80 \%$ of their ATP within 15 min. Essentially, similar kinetics of ATP loss were observed with concentrations as low as $0.5 \mu \mathrm{M}$ (not shown). Glycolysis did not seem to be affected by TBT in J urkat cells, since ATP levels were maintained over $1 \mathrm{~h}$ in the presence of glucose, regardless of whether oligomycin was present (Figure $1 \mathrm{~A}$ ).

We further investigated the sensitivity of glycolytic ATP production to TBT by exposing J urkat cells to a high concentration of TBT $(10 \mu \mathrm{M})$, known to trigger necrosis instead of apoptosis (20). Even under such conditions, glycolytic ATP production was maintained for $\geq 60 \mathrm{~min}$ (Figure 1B), i.e., until the cells began to show signs of death.

Conversion of TBT-Induced Apoptosis to Necrosis in ATP-Depleted Cells. TBT concentrations of $0.5-2 \mu \mathrm{M}$ consistently elicited apoptosis in J urkat cells maintained in PNG medium and glucose, i.e., under conditions when intracellular ATP concentrations were maintained (Figures $1 A$ and $2 A$ ). The mitochondrial ATP synthase inhibitor oligomycin affected neither apoptosis (Figure 2A) nor cellular ATP levels (Figure 1A) in glucose-containing medium. Thus, mitochondrial ATP production was required for neither maintenance of ATP levels nor apoptosis in this experimental setup.

Conversely, TBT-triggered apoptosis was entirely prevented in the absence of glycolytic ATP production (culture in PNG medium). Under these conditions, addition of TBT itself was sufficient to shut down the mitochondrial ATP production, thereby preduding completion of the apoptotic process. In addition, TBT-triggered apoptosis was entirely prevented in cells that were predepleted of ATP before exposure to TBT by incubation in medium containing pyruvate and oligomycin as the only energy source. Detailed analysis of the mode of cell death over an extended time period $(250 \mathrm{~min})$ revealed that TBT triggered delayed necrosis in those cells that had been rescued from apoptosis by ATP depletion (Figure 2B). Cells depleted of their ATP to the same extent, but not challenged with TBT, retained their viability throughout the experimental period (29).

Changes in the Mitochondrial Membrane Potential. An early loss of mitochondrial membrane potential

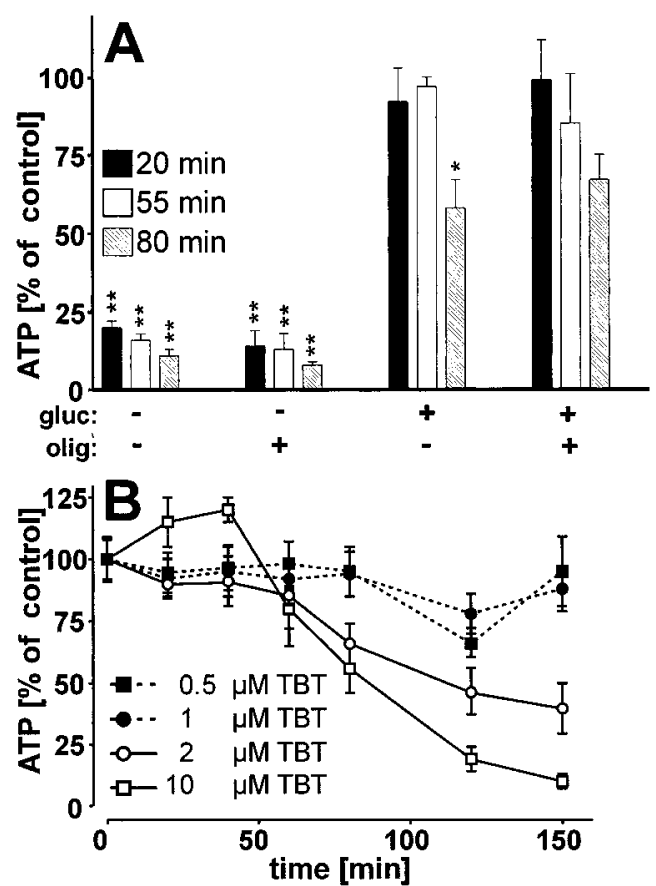

Figure 1. Modulation of intracellular ATP content by TBT. (A) J urkat cells, cultured in PNG medium in the absence or presence of glucose (gluc; $10 \mathrm{mM}$ ), were preincubated with 0 or $2.5 \mu \mathrm{M}$ oligomycin (olig) and exposed to $2 \mu \mathrm{M}$ TBT. The ATP level was measured after 15,55 , and $80 \mathrm{~min}$, and the cellular ATP content is presented as a percentage of untreated controls $\left(100 \%=4.5 \mathrm{nmol} / 10^{6}\right.$ cells). Data represent means \pm the standard deviation from three independent experiments. The similarity of ATP values to those of untreated controls was tested by a t test. For bars marked with one asterisk, $\mathrm{p}<0.05$. For bars marked with two asterisks, $p<0.01$. (B) J urkat cells were exposed to different concentrations of TBT in PNG medium supplemented with $10 \mathrm{mM}$ glucose, and the cellular ATP content was followed for $150 \mathrm{~min}$. Data represent the means \pm the standard deviation from triplicate determinations.

$(\Delta \Psi)$ is typical of TBT-induced apoptosis. We examined whether ATP depletion had an effect on this early feature of TBT-induced cytotoxicity. J urkat cells were stained with the $\Delta \Psi$-sensitive dye TMRE and imaged by confocal microscopy. After exposure to TBT for only $10 \mathrm{~min}(1 \mu \mathrm{M})$, cells in glucose-containing medium lost fluorescence, i.e., $\Delta \Psi$. After $45 \mathrm{~min},>75 \%$ of the cells had lost their $\Delta \Psi$ (Figure $3 \mathrm{~A}$ ). In contrast, the mitochondria of cells in glucose-free medium retained their $\Delta \Psi$ at $10 \mathrm{~min}$, and $>60 \%$ of the cells were still fluorescent after $45 \mathrm{~min}$. Further, J urkat cells treated with BA had hyperfluorescent mitochondria at $10 \mathrm{~min}$ and were significantly protected at $45 \mathrm{~min}$ (Figure 3A). To obtain an independent set of quantitative data, the number of cells exhibiting collapsed $\Delta \Psi$ was also analyzed by FACS. At late time points ( $90 \mathrm{~min}$ ), cells incubated in any medium had largely lost their $\Delta \Psi$. However, at early time points, ATPdepleted cells were significantly protected from TBTtriggered loss of $\Delta \Psi$ (Figure 3B).

As a complementary approach to FACS analysis, we used a "fluorescence unquenching" technique. Cells were loaded in a fluorimeter cuvette with a high TMRE concentration, leading to fluorescence quenching within mitochondria. Thus, the loss of $\Delta \Psi$ results in TMRE release from mitochondria and increased fluor escence in the cuvette (37). Addition of TBT to cells in glucosecontaining medium led to an immediate increase in TMRE fluorescence, followed by a phase of a more gradual increase to the level of complete depolarization 

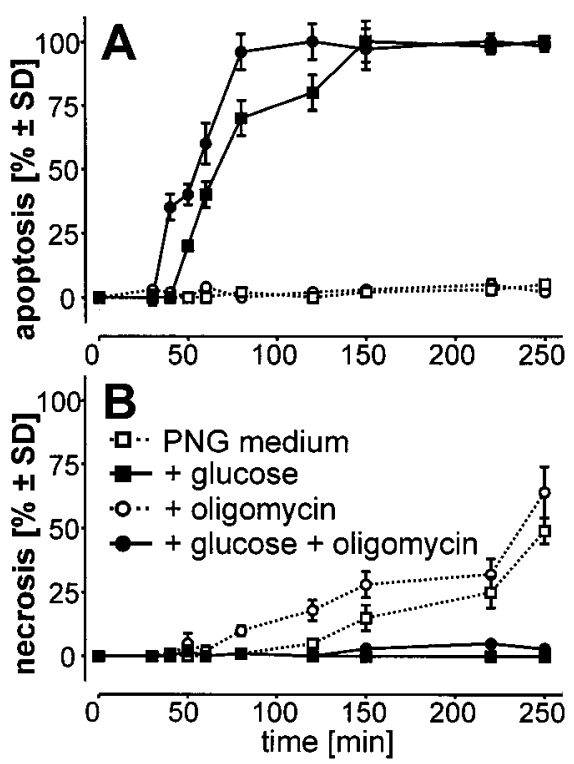

Figure 2. TBT-induced apoptosis or necrosis, depending on the metabolic situation. J urkat cells, cultured in the absence or presence of glucose $(10 \mathrm{mM})$, were preincubated with 0 or $2.5 \mu \mathrm{M}$ oligomycin and exposed to $2 \mu \mathrm{M}$ TBT. The percentage of apoptotic (A) and necrotic (B) cells was counted at different times after staining of the cultures with the fluorescent chromatin dyes $\mathrm{H}-33342$ and SYTOX. Data are means \pm the standard deviation of five to seven experiments.

(no further increase after addition of FCCP). In cells incubated in glucose-free medium, a primary increase in fluorescence was followed by a stabilization phase, and after $1 \mathrm{~h}$, a partial $\Delta \Psi$ was still maintained (TMRE fluorescence was significantly increased by subsequent FCCP addition) (Figure 4A).

Mitochondrial Swelling and Distribution of Cytochrome c. The initial changes in the mitochondria of TBT-treated J urkat cells were also reflected by the pattern of distribution of cytochrome $c$ in the cells, as detected by immunofluorescence. Exposure of cells to TBT in the presence of glucose for only $10 \mathrm{~min}$ triggered mitochondrial rounding and swelling, as shown by the ring-shaped pattern of cytochrome c staining. Although the release of cytochrome c into the cytosol had al ready occurred at that time, a considerable amount of immunoreactive cytochrome c seemed to still be localized on the mitochondrial membranes (Figure 4B). The ringshaped structures formed by cytochrome c colocalized with the mitochondrial marker Mitotracker Red (data not shown). The cytochrome c pattern exhibited in cells incubated in the absence of glucose indicated some swelling of mitochondria, but there was neither a release of cytochrome c into the cytosol nor the ballooning, circular structures seen in the presence of glucose. At later time points, $\geq 60 \mathrm{~min}$, cytochrome $\mathrm{c}$ was shown to be detached completely from mitochondria, independently of the presence of glucose (Figure 4B).

The Rapid Release of Mitochondrial Proteins Requires ATP. An early step in the apoptotic program is the rel ease of proapoptotic proteins from the mitochondrial intermembrane space, such as AIF (38) or cytochrome c (39). This is accompanied by the rel ease of other proteins primarily located within the same subcellular compartment, such as adenylate kinase (ADK) (33). We followed the loss of ADK as an easily quantifiable indicator for the loss of the barrier function of the outer mitochondrial membrane. TBT triggered a release of
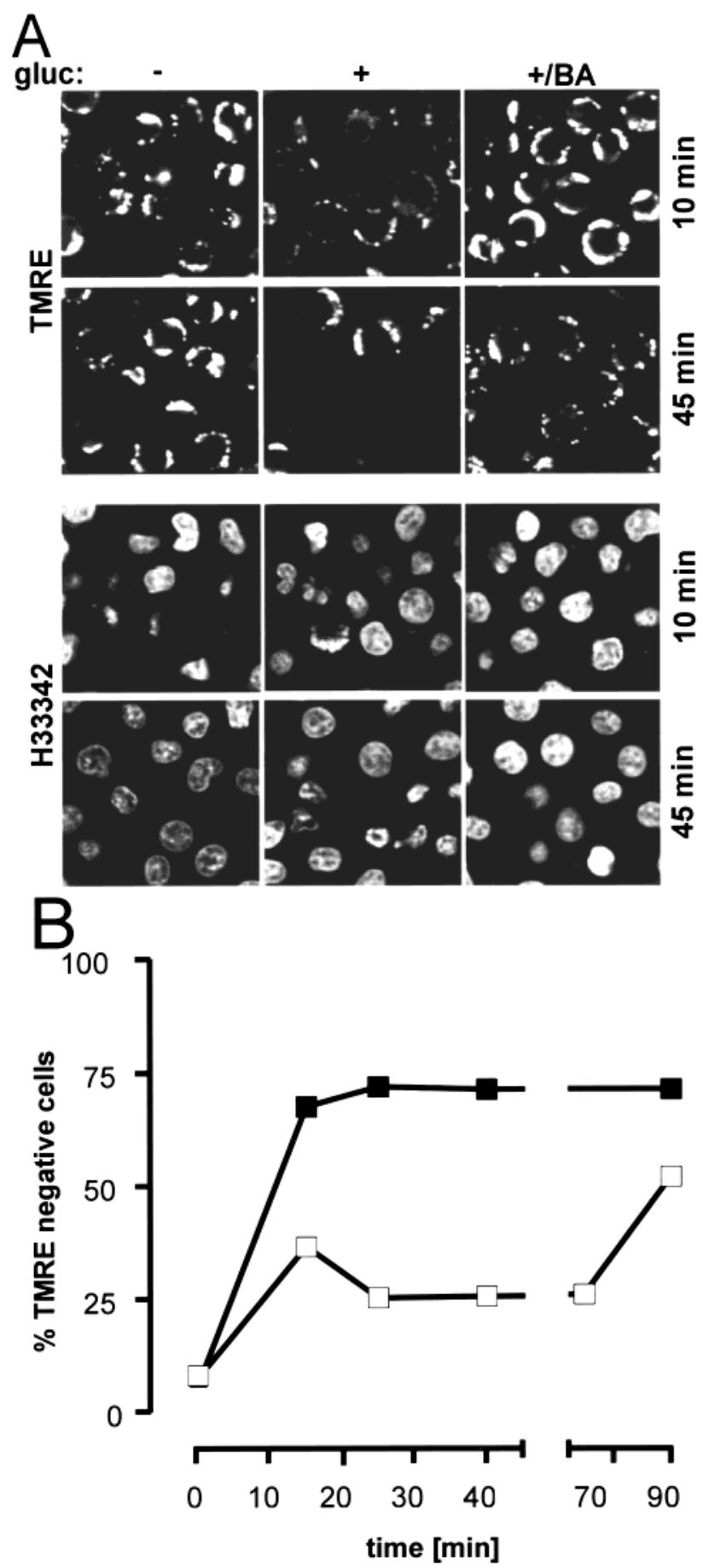

Figure 3. Effects of TBT on mitochondrial membrane potential in the presence or absence of glucose. (A) J urkat cells were suspended in PNG medium and stained with $5 \mathrm{nM}$ TMRE and $250 \mathrm{ng} / \mathrm{mL} \mathrm{H}-33342$ in the presence or absence of glucose (10 $\mu \mathrm{M})$ or bongkrekic acid (BA, $50 \mu \mathrm{M})$. Ten minutes and $45 \mathrm{~min}$ after exposure to TBT $(1 \mu \mathrm{M})$, cells were imaged on a confocal mi croscope. Mitochondrial and nudear staining of the same cells is shown in the top and bottom panels, respectively. All experiments were performed at least three times, and representative images are shown. (B) FACS analysis of cells exposed to TBT $(1 \mu \mathrm{M})$ in PNG medium with (black symbols) or without (white symbols) glucose $(10 \mathrm{mM})$. Cells were analyzed at different time points for mitochondrial accumulation of TMRE, and the percentage of negative cells (low $\Delta \Psi_{\text {mit }}$ ) is indicated. The experiment was performed twice with similar results, and average percentages from both experiments are shown.

ADK within $10 \mathrm{~min}$, when glucose was present in the incubation medium. Under conditions of ATP depletion, however, the activity of ADK in the cytosol did not 


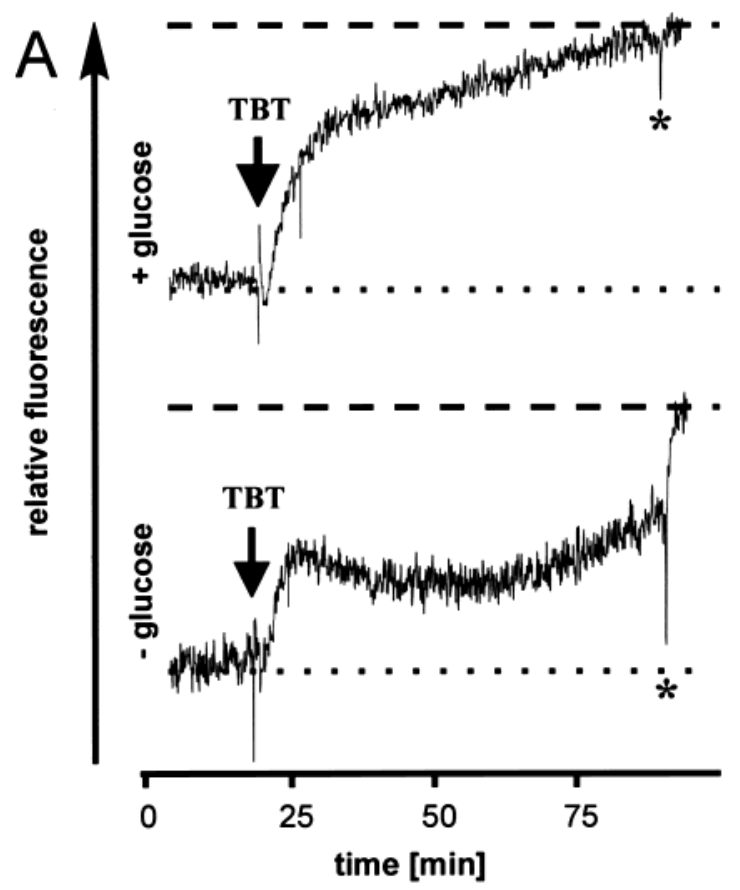

B
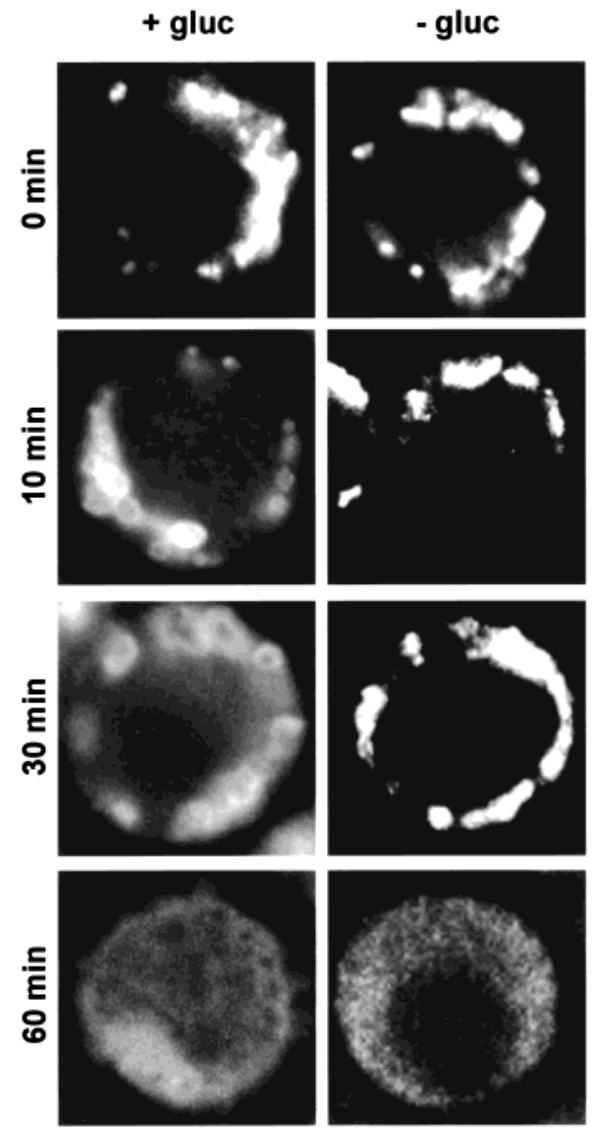

Figure 4. Fast mitochondrial swelling and cytochrome $c$ redistribution after TBT exposure. (A) The extent of TMRE unquenching was measured after exposure of J urkat $T$ lymphocytes to TBT in the absence or presence of glucose. Cells were suspended in PNG medium and stained with $20 \mathrm{nM}$ TMRE. After equilibration, TBT $(1 \mu \mathrm{M})$ was added (arrows). At the end of the experiment, the uncoupling agent FCCP $(*)$ was used to determine the remaining $\Delta \Psi_{\text {mit. }}$ (B) J urkat T Iymphocytes were fixed in paraformaldehyde $(4 \%)$ at different time points after exposure to TBT (in the presence or absence of glucose). They were immunostained for cytochrome $c$, and representative cells are shown.

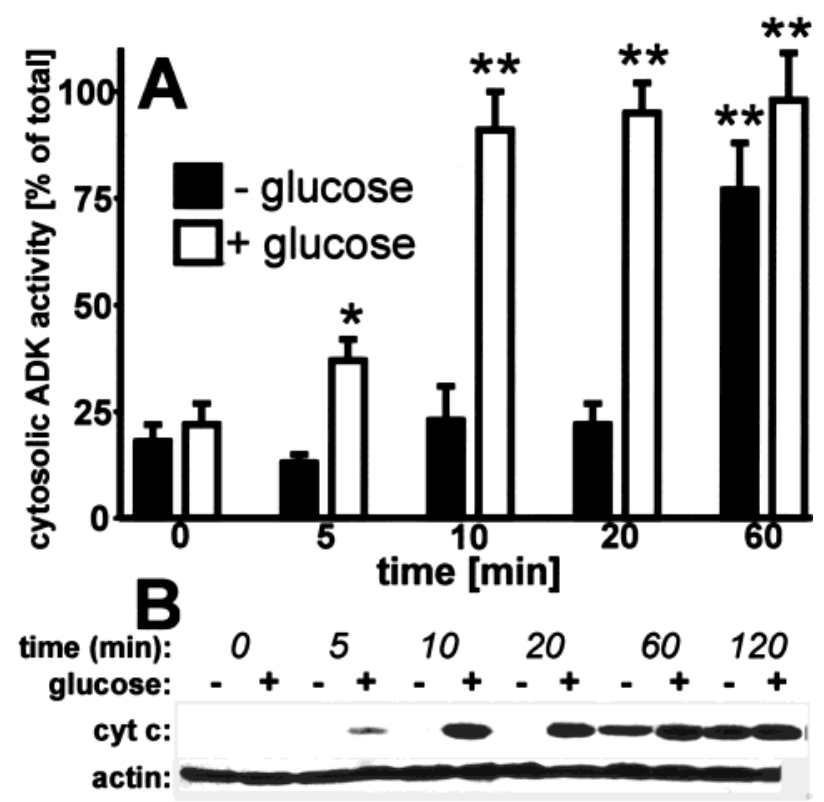

Figure 5. Release of mitochondrial proteins to the cytosol upon exposure of cells to TBT. J urkat T lymphocytes, cultured in PNG medium in the absence or presence of glucose $(10 \mathrm{mM})$, were stimulated with TBT $(2 \mu \mathrm{M})$ for the indicated times. The cytoplasm was separated rapidly from other organelles at the indicated times. (A) ADK activity was determined in the cytoplasmic fraction. Data are means \pm the standard deviation from three experiments, and are indicated as a percentage of the total enzymatic activity that can be released by Triton X-100 $(0.2 \%)$. Cytoplasmic ADK activities were analyzed for their similarity to the values at time zero by a t test. For bars marked with one asterisk, $p<0.05$. F or bars marked with two asterisks, $\mathrm{p}<0.01$. (B) The cytoplasmic content of cytochrome c (cyt c) was determined by immunoblot analysis. Actin was detected as a control for equal sampling and loading from the same samples. Data are representative of two similar experiments.

increase until the sample had been incubated for $60 \mathrm{~min}$ (Figure 5A). Similar findings were obtained when the rel ease of cytochrome c from mitochondria into the cytosol was examined. In cells that are able to maintain their initial ATP level, cytochrome c was translocated within minutes of exposure to TBT, while an extended delay was observed under conditions of ATP depletion (Figure 5B).

Modification of TBT-Induced Cell Death by Bongkrekic Acid. The adenine nucleotide translocator (ANT) is one of the key mitochondrial proteins involved in permeability transition and, possibly, in changes leading to the release of mitochondrial proteins. Accordingly, we tested whether bongkrekic acid (BA), a cell permeable inhibitor of ANT, would reproduce the effects of ATP depletion on cytochrome c release and apoptosis. J urkat cells were exposed to TBT in PNG medium supplemented with glucose. Under these conditions, pretreatment with BA resulted in almost complete prevention of apoptosis during the first $150 \mathrm{~min}$. After this time, the level of apoptosis in unprotected cells had reached a maximum (Figure $6 \mathrm{~A}$ ). This initial protection was associated with a delayed cytochrome c release, similar in extent to the one observed in ATP-depleted cells (F igure 6B; compare to Figure 5). When the extent of cell death was examined after extended times (stimulation for more than $3 \mathrm{~h}$ ), BA-treated cells also died eventually by apoptosis. A switch to necrosis was not observed.

$\mathrm{Bcl}-2$ is an antiapoptotic protein with a mitochondrial site of action. To compare the effects of BA with those of 

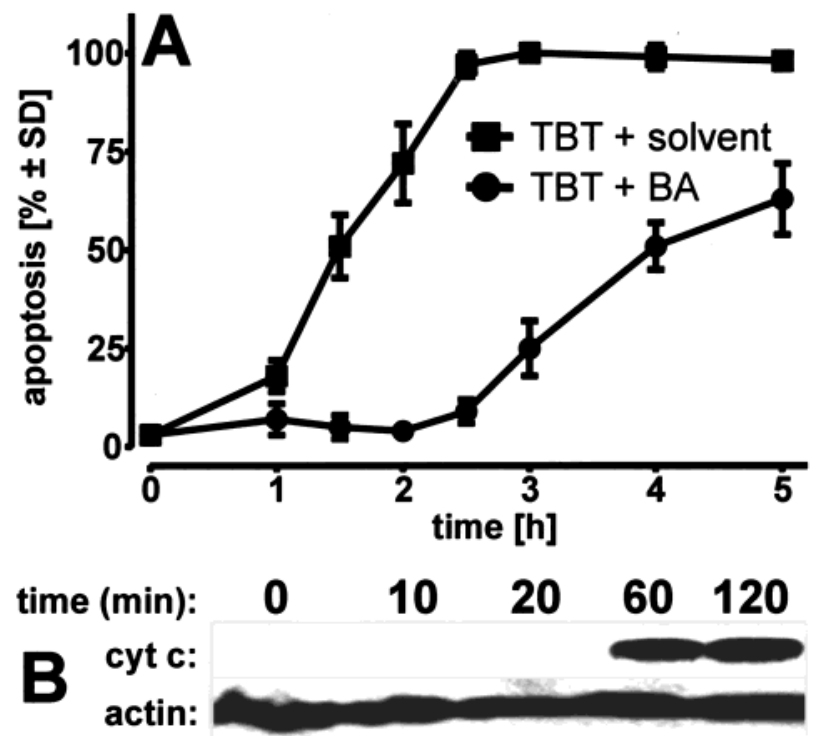

Figure 6. Delay of TBT-triggered apoptosis by bongkrekic acid. (A) J urkat cells were incubated in PNG medium supplemented with glucose $(10 \mathrm{mM})$. After preincubation with solvent $(0.1 \mathrm{mM}$ $\mathrm{NH}_{3}$, final concentration) or bongkrekic acid (BA, $50 \mu \mathrm{M}$ ) for 30 min, TBT ( $2 \mu \mathrm{M}$ final) was added. Cells were stained with the fluorescent chromatin dyes $\mathrm{H}-33342$ and SYTOX at the indicated times, and the extent and mode of cell death were determined. Data are means \pm the standard deviation from triplicate determinations, and are representative of seven similar experiments. (B) Cytosolic fractions were prepared from cells at different times after stimulation with TBT in medium containing glucose and $50 \mu \mathrm{M}$ BA. The cytochrome c content was analyzed by Western blot analysis.

Bcl-2, we used J urkat cells over expressing Bcl-2. At TBT concentrations of $\geq 1 \mu \mathrm{M}, \mathrm{BCl}-2$ had no significant effect on the kinetics and extent of apoptosis. The same lack of protection was noted for $\mathrm{BCl}-\mathrm{X}_{\mathrm{L}}$ overexpressing cells (not shown). Only at lower TBT concentrations $(0.5 \mu \mathrm{M})$ did $\mathrm{Bcl}-2$ significantly $(\mathrm{p}<0.01)$ sl ow apoptosis $(15 \pm 5$ and $31 \pm 4 \%$ apoptosis after 180 and $240 \mathrm{~min}$ in $\mathrm{Bcl}-2$ cells, respectively, vs $50 \pm 1$ and $68 \pm 7 \%$ after 180 and 240 min in vector control cells, respectively).

Prevention of Caspase Activation in ATP-Depleted Cells. The activation of DEVD-afc cleaving caspases seems to determine the morphol ogy of apoptotic cells (40). One of the key events in their activation seems to be the formation of an ATP-dependent apoptosome complex (39). Since we observed that the intracellular ATP level affected the shape, mode, and morphology of TBTtriggered cell death, we examined whether this was associated with differential caspase activation. In fact, pronounced and rapid stimulation of DEVD-afc cleavage (Figure 7A) and processing of procaspase-3 (Figure 7B) to the active protease were observed in cells exposed to TBT in PNG medium supplemented with glucose. In contrast, there was no caspase activation under ATPdepleting conditions in pure PNG medium, even though cytochrome c had been fully released after $60 \mathrm{~min}$ (Figure 5B).

In cultures treated with BA in the presence of glucose, intracellular ATP was maintained at a level of $88 \pm 7 \%$ after $60 \mathrm{~min}$ and $68 \pm 4 \%$ after $120 \mathrm{~min}$, and then slowly dropped. Consistent with the relatively high intracellular ATP concentrations and the release of cytochrome $c$ to the cytoplasm, caspases were activated in BA-treated cells starting $120 \mathrm{~min}$ after exposure to TBT (Figure 7). In Bcl-2-expressing cells, caspase activation was delayed
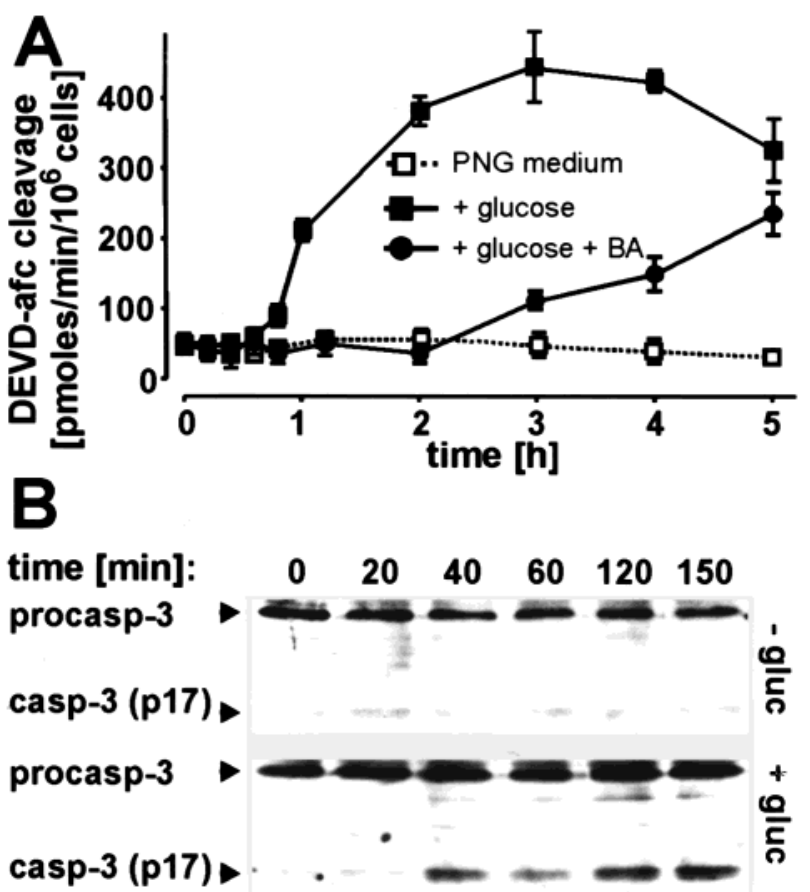

Figure 7. Activation of DEVD-afc-cleaving caspases by TBT. (A) J urkat cells were incubated in either pure PNG medium, or medium supplemented with glucose $(10 \mathrm{mM})$, or glucose and BA $(50 \mu \mathrm{M})$. At the indicated times after addition of TBT $(2 \mu \mathrm{M})$, cells were harvested, and the DEVD-afc-cleaving activity was determined fluorimetrically in cell lysates. Data are means \pm the standard deviation from two to four experiments. (B) Cells challenged with TBT in PNG medium (-gluc) or in PNG medium supplemented with glucose (+gluc) were harvested after the indicated times, and caspase- 3 was detected by immunoblot analysis. Increased immunoreactivity for the p17 band indicates processing of procaspase $3(32 \mathrm{kDa}$ ) to the active protease. The blots shown are representative of two similar experiments.

in a manner similar to that after BA treatment for about 90 min when $0.5 \mu \mathrm{M}$ TBT was used. No Bcl-2 effect was seen with TBT concentrations of $>1 \mu \mathrm{M}$ (data not shown).

\section{Discussion}

Toxicants, such as TBT, may trigger apoptosis or necrosis in various cell types. It is now well established that the dose of the toxin, or the intensity of the insult, may determine the manner in which a cell dies. For instance, high concentrations of a redox-active compound (24), of mitochondrial toxins (41), or of NO donors (42) may trigger necrosis, while low concentrations of the same agents cause apoptosis. A similar correlation has been found with TBT (20). Despite this knowledge, it has remained unclear which parameters are responsible for determining that the same concentration of a chemical may trigger either apoptosis or necrosis in the same cell type. Thus, the intracellular determinants involved in the molecular switch between these two modes of cell death still await elucidation.

One experimental method for provoking a switch from apoptosis to necrosis is the pharmacological inhibition of caspases (26). Another established experimental protocol uses mitochondrial inhibitors that deplete ATP and, thereby, prevent the activation of caspases downstream of the Apaf-1-cytochromec c-dATP apoptosome complex $(29,30,43)$. Here, we show that the same TBT concentration can trigger either apoptosis or necrosis in J urkat 
$T$ cells depending on the ability of the cells to generate ATP from different energy substrates. This suggests that intracellular ATP, and the relative importance of different ATP-supplying pathways, may be among the intracellular determinants responsible for the mode of cellular demise triggered by chemicals.

We have established at least two different ATPrequiring steps in TBT-treated J urkat cells at which ATP depletion appeared to retard, or stop, the execution of the apoptotic program and to direct cel Is toward delayed necrosis. The first step involved the rel ease of cytochrome c from mitochondria. Release of this protein into the cytosol is essential for apoptosome formation and for Apaf-1-caspase-9-mediated apoptosis (44). Under conditions of ATP depletion in TBT-treated cells, the appearance of cytochrome $c$ in the cytoplasm was substantially delayed. This retardation was paralleled by a similarly delayed release of ADK, and the release of cytochrome $c$ also reflected a delayed loss of $\Delta \Psi$, and decreased swelling of the mitochondria. The delayed cytochrome c translocation to the cytosol did not prevent death, but cells died later by necrosis.

A second step was also affected by ATP depletion. DEVD-afc-cl eaving caspases were only activated in cells grown in glucose-containing medium, i.e., when the ATP level was not depleted. Since DEVD-afc-cleaving caspases, such as caspase-3, play an essential role in TBTinduced apoptosis $(45,51)$, and seem to be essential for determining the apoptotic morphology in general (40), the observed prevention of their activation may alone be sufficient to prevent apoptosis.

The results of this investigation demonstrate that TBT completely and selectively inhibits the production of ATP in the mitochondria of J urkat cells, while glycolysis is little affected during the first 70-90 min after exposure to the compound. Thus, TBT does not necessarily deplete cells of ATP, provided that they are supplied with glucose and have a high glycolytic capacity. On the other hand, TBT is an efficient ATP-depleting agent in cells with low glycolytic capacity, or in cells mainly energized by mitochondrial substrates such as ketone bodies. F or example, in HEL-30 murine epidermal cells, TBT may al so deplete ATP within minutes in the presence of glucose (14). These observations are in line with earlier studies with isolated mitochondria showing that trialkyltin compounds decrease the rate of mitochondrial uptake of $\mathrm{NAD}^{+}$-linked substrates, such as pyruvate, malate, citrate, and $\beta$-hydroxybutyrate (46), and that TBT inhibits the ol igomycinsensitive F 1-ATP synthase $(19,47)$. A selective targeting of mitochondria by TBT is furthermore suggested by studies of gene regulation, relevant to the skin irritant properties of low TBT concentrations. Here, TBT seems to trigger a series of events involving mitochondrial production of reactive oxygen species, activation of the transcription factor NF-kB, and subsequent cytokine production (13).

The severe loss of cellular ATP seems to be sufficient to switch apoptosis to necrosis in TBT-challenged cells, although ATP depletion is not a prerequisite for this switch. For instance, cells exposed to high TBT concentrations $(10 \mu \mathrm{M})$ in glucose-containing medium died by necrosis, although they maintained their ATP level for at least 60 min (cf. Figure 1B). Here, other factors may interfere with the termination of the apoptotic program. For instance, caspases may be inhibited by oxidative stress (48), by direct binding of chemicals to essential thiol groups (49), or by increased ion influx under necrotic conditions, which precludes caspase activation (50). In such cases, the loss of ion homeostasis or the caspaseindependent consequences of mitochondrial failure may eventually lead to cell death.

Although organotin compounds themselves are very poorly reactive with monothiols, they bind rapidly to vicinal dithiols (51). In line with this, they have been shown to inactivate caspases at concentrations of around $10 \mu \mathrm{M}$ (i.e., the concentrations triggering necrosis) in a manner similar to that of the archetypical vicinal dithiol reactive compound phenylarsine oxide (51). This suggests one possible mechanism by which high TBT concentrations may prevent apoptosis and switch cell death to necrosis in the presence of high intracellular ATP concentrations. In addition, it may be speculated that TBT itself may interact with the ANT and trigger the mitochondrial permeability transition, since the ANT is controlled by a critical pair of vicinal thiols (52).

The ANT has been recently suggested to play a central role in apoptosis for the opening of the mitochondrial megachannels, for mitochondrial swelling, and for the induction of apoptosis (53-55). In addition to its carrier function for adenine nucleotides, the ANT may be involved in the formation of pores in the inner mitochondrial membrane, and this structural function seems to be favored by the conformation fixed by atractyloside, and precluded in the conformation fixed by BA $(53,54)$. It is possible that the membrane orientation, structure, or reorganization of ANT is also affected by cellular ATP depletion. In fact, addition of BA delayed the loss of $\Delta \Psi$ as well as the rel ease of cytochrome $c$ from mitochondria in a manner similar to that seen in cells under conditions limiting cellular ATP synthesis. This supports the proposed involvement of ANT-dependent events, such as the mitochondrial permeability transition, in TBT-induced apoptosis in J urkat cells, and provides some preliminary evidence for a potential role of ANT in mediating cellular effects of ATP depletion.

Interestingly, BA prevented cytochrome c release, the activation of caspases, and the induction of apoptosis only transiently. This suggests that prolonged exposure to TBT induces mitochondrial damage also when the ANT is inhibited, and fixed in a conformation that is unfavorable for pore formation. Other events, such as the cytochrome c-independent release of mitochondrial apoptosis-inducing factor (AIF) (56) or increased free intracellular $\mathrm{Ca}^{2+}$ concentrations (13) may trigger mitochondrial outer membrane permeabilization and further apoptotic events. In some cells, mitochondria may be affected downstream of the TBT-induced disturbance of $\mathrm{Ca}^{2+}$ homeostasis $(13,16)$. This suggests that even when mitochondria are stabilized, TBT may eventually exert its toxicity by mechanisms directly triggered by elevated intracellular $\mathrm{Ca}^{2+}$ levels (15).

Notably, the protection by $\mathrm{BCl}-2$ family proteins was as transient as that by BA. In fact, the delay of caspase activation and the delay of apoptosis were significantly more robust and more pronounced with $\mathrm{BA}$ than with $\mathrm{BCl}$-2. This suggests that TBT-induced apoptosis is, at least in part, independent of the control by $\mathrm{BCl}-2$ and similar antiapoptotic proteins. It appears to resemble type I CD95-mediated apoptosis observed in several lymphoma cells (31) or the cell death observed in transplanted dopaminergic neurons (57). 
In summary, we have shown here that TBT targets the mitochondria in J urkat $T$ cells within 1-2 min of addition. When glycolytic ATP production was maintained, severe mitochondrial swelling was evident within less than $10 \mathrm{~min}$. Subsequently, the mitochondria seemed to go through a transition state, where some cytochrome c was still loosely attached to the outside of mitochondrial structures, al though the outer mitochondrial membrane was permeable to proteins, as evidenced by the release of adenylate kinase. Subsequently, cytochrome c was distributed throughout the cytoplasm and caspases were activated. In contrast, under conditions of ATP depletion triggered by TBT itself in the absence of glycolytic substrates, the mitochondrial release of proteins and the loss of the mitochondrial membrane potential were delayed. More important, caspase activation and apoptosis were completely blocked and cell death occurred by necrosis. Thus, the availability of glycolytic ATP seems to largely determine the overall mode and mechanisms of TBT-triggered cell death in J urkat T cells.

Acknowledgment. We are grateful to J eanette Peterke and Heike Naumann for the technical assistence, to Dr. J . A. Duine (Delft University of Technology, Delft, The Netherlands) for providing bongkrekic acid, to Dr. D. W. Nicholson (Merck Frost Center for Therapeutic Research) for providing us with anti-caspase-3 antibodies, to Dr. S. Korsmeyer (Dana F arber Institute) for providing transfected J urkat cells, and to Dr. I. Cotgreave for critically reading the manuscript. This study was supported by DFG Grants We686/18-1, Ni519/2-1, and Ni519/1-1, by EEC Grants ENV4-CT96-0169, BMH4CT972410, and 12029-97-06 F 1ED ISP D, and by the Fonds der Chemischen Industrie.

\section{References}

(1) World Health Organization (1980) Environmental Health Criteria 15. Tin and organotin compounds: A preliminary review, World Health Organization, Geneva, Switzerland.

(2) World Health Organization (1990) Environmental Health Criteria 116. Tributyltin compounds, World Health Organization, Geneva, Switzerland.

(3) Boyer, I. J . (1989) Toxicity of dibutyltin, tributyltin and other organotin compounds to humans and to experimental animals. Toxicology 55, 253-298.

(4) Fent, K. (1996) E cotoxicology of organotin compounds. Crit. Rev. Toxicol. 26, 1-117.

(5) Wax, P. M., and Dockstader, L. (1995) Tributyltin use in interior paints: a continuing health hazard. J . Toxicol., Clin. Toxicol. 33, 239-241.

(6) Seinen, W., and Willems, M. I. (1976) Toxicity of organotin compounds. I. Atrophy of thymus and thymus-dependent lymphoid tissue in rats fed di-n-octyltindichloride. Toxicol. Appl. Pharmacol. 35, 63-75.

(7) Seinen, W., Vos, J. G., van Krieken, R., Penninks, A., Brands, R., and Hooykaas, H. (1977) Toxicity of organotin compounds. III. Suppression of thymus-dependent immunity in rats by di-nbutyltindichloride and di-n-octyltindichloride. Toxicol. Appl. Pharmacol. 42, 213-224.

(8) Snoeij, N. J ., Penninks, A. H., and Seinen, W. (1988) Dibutyltin and tributyltin compounds induce thymus atrophy in rats due to a selective action on thymic lymphoblasts. Int. J . I mmunopharmacol. 10, 891-899.

(9) Vos, J . G., de Klerk, A., Krajnc, E. I., Kruizinga, W., van Ommen, B., and Rozing, J . (1984) Toxicity of bis(tri-n-butyltin)oxide in the rat. II. Suppression of thymus-dependent immune responses and of parameters of nonspecific resistance after short-term exposure. Toxicol. Appl. Pharmacol. 75, 387-408.

(10) Aw, T. Y., Nicotera, P., Manzo, L., and Orrenius, S. (1990) Tributyltin stimulates apoptosis in rat thymocytes. Arch. Biochem. Biophys. 283, 46-50.

(11) Raffray, M., McCarthy, D., Snowden, R. T., and Cohen, G. M. (1993) Apoptosis as a mechanism of tributyltin cytotoxicity to thymocytes: relationship of apoptotic markers to biochemical and cellular effects. Toxicol. Appl. Pharmacol. 119, 122-130.

(12) Aldridge, W. N., and Cremer, J . E. (1955) The biochemistry of organo-tin compounds. Diethyltinchloride and trethyltin sulphate Biochem. J . 61, 406-418.

(13) Corsini, E., Viviani, B., Marinovich, M., and Galli, C. L. (1997) Role of mitochondria and calcium ions in tributylin-induced gene regulatory pathways. Toxicol. Appl. Pharmacol. 145, 74-81.

(14) Marinovich, M., Viviani, B., and Galli, C. L. (1990) Reversibility of tributyltin-chloride-induced protein synthesis inhibition after ATP recovery in HEL-30 cells. Toxicol. Lett. 52, 311-317.

(15) Viviani, B., Rossi, A. D., Chow, S. C., and Nicotera, P. (1995) Organotin compounds induce calcium overload and apoptosis in PC12 cells. Neurotoxicology 16, 19-26.

(16) Chow, S. C., Kass, G. E., McCabe, M. J ., J r., and Orrenius, S. (1992) Tributyltin increases cytosolic free $\mathrm{Ca}^{2+}$ concentration in thymocytes by mobilizing intracellular $\mathrm{Ca}^{2+}$, activating a $\mathrm{Ca}^{2+}$ entry pathway, and inhibiting $\mathrm{Ca}^{2+}$ efflux. Arch. Biochem. Biophys. 298, 143-149.

(17) Skilleter, D. N. (1976) The influence of adenine nucleotides and oxidisable substrates on triethyltin-mediated chloride uptake by rat liver mitochondria in potassium chloride media. Biochem. J. 154, 271-276.

(18) Selwyn, M. J ., Dawson, A. P., Stockdale, M., and Gains, N. (1970) Chloride-hydroxide exchange across mitochondrial, erythrocyte and artificial lipid membranes mediated by trialkyl- and triphenyltin compounds. Eur. J . Biochem. 14, 120-126.

(19) Aldridge, W. N., and Street, B. W. (1970) Oxidative phosphorylation. The specific binding of trimethyltin and triethyltin to rat liver mitochondria. Biochem. J . 118, 171-179.

(20) Stridh, H., Kimland, M., J ones, D. P., Orrenius, S., and Hampton, M. B. (1998) Cytochrome c release and caspase activation in hydrogen peroxide and tributyltin-induced apoptosis. FEBS Lett. 429, 351-355.

(21) Leist, M., and Nicotera, P. (1997) The shape of cell death. Biochem. Biophys. Res. Commun. 236, 1-9.

(22) Green, D., and Kroemer, G. (1998) The central executioners of apoptosis: caspases or mitochondria? Trends Cell Biol. 8, 267271.

(23) Nicotera, P., Leist, M., and Manzo, L. (1999) Neuronal cell dearth: a demise with different shapes. Trends Pharmacol. Sci. 20, 46-51.

(24) Dypbukt, J . M., Ankarcrona, M., Burkitt, M., Sjoholm, A., Strom, K., Orrenius, S., and Nicotera, P. (1994) Different prooxidant levels stimulate growth, trigger apoptosis, or produce necrosis of insulin-secreting rinm5f cells. the role of intracellular polyamines. J . Biol. Chem. 269, 30553-30560.

(25) Melino, G., Bernassola, F., Knight, R. A., Corasaniti, M. T., Nistico, G., and Finazzi-Agro, A. (1997) S-Nitrosylation regulates apoptosis. Nature 388, 432-433.

(26) Hirsch, T., Marchetti, P., Susin, S. A., Dallaporta, B., Zamzami, N., Marzo, I., Geuskens, M., and Kroemer, G. (1997) The apoptosis-necrosis paradox. Apoptogenic proteases activated after mitochondrial permeability transition determine the mode of cell death. Oncogene 15, 1573-1581.

(27) Leist, M., Single, B., Naumann, H., Fava, E., Simon, B., Kuhnle S., and Nicotera, P. (1999) Nitric oxide inhibits execution of apoptosis at two distinct ATP-dependent steps upstream and downstream of mitochondrial cytochrome $\mathrm{c}$ release. Biochem. Biophys. Res. Commun. 258, 215-221.

(28) Leist, M., Single, B., Naumann, H., Fava, E., Simon, B., Kuhnle, S., and Nicotera, P. (1999) Inhibition of mitochondrial ATP generation by nitric oxide switches apoptosis into necrosis. Exp. Cell Res. 249, 396-403.

(29) Leist, M., Single, B., Castoldi, A. F., Kuhnle, S., and Nicotera, P. (1997) Intracellular adenosine triphosphate (ATP) concentration: a switch in the decision between apoptosis and necrosis. J . Exp. Med. 185, 1481-1486.

(30) Eguchi, Y., Shimizu, S., and Tsujimoto, Y. (1997) Intracellular ATP levels determine cell death fate by apoptosis or necrosis. Cancer Res. 57, 1835-1840.

(31) Scaffidi, C., Fulda, S., Srinivasan, A., Friesen, C., Li, F., Tomaselli, K. J ., Debatin, K. M., Krammer, P. H., and Peter, M. E. (1998) Two CD95 (APO-1/F as) signaling pathways. EMBO J . 17, 16751687.

(32) Leist, M., Fava, E., Montecucco, C., and Nicotera, P. (1997) Peroxynitrite and NO-donors induce neuronal apoptosis by eliciting autocrine excitotoxicity. Eur. J . Neurosci. 9, 1488-1498.

(33) Single, B., Leist, M., and Nicotera, P. (1998) Simultaneous release of adenylate kinase and cytochrome $\mathrm{c}$ in cell death. Cell Death Differ. 5, 1001-1003.

(34) Bergmeyer, H. U. (1984) Methods of Enzymatic Analysis, Verlag Chemie, Weinheim, Germany. 
(35) Thornberry, N. A. (1994) Interleukin-1 beta converting enzyme. Methods Enzymol. 244, 615-631.

(36) Metivier, D., Dallaporta, B., Zamzami, N., Larochette, N., Susin, S. A., Marzo, I., and Kroemer, G. (1998) Cytofluorometric detection of mitochondrial alterations in early CD95/Fas/APO-1triggered apoptosis of J urkat T Iymphoma cells. Comparison of seven mitochondrion-specific fluorochromes. I mmunol. Lett. 61 157-163.

(37) Ichas, F., J ouaville, L. S., and Mazat, J . P. (1997) Mitochondria are excitable organelles capable of generating and conveying electrical and calcium signals. Cell 89, 1145-1153.

(38) Zamzami, N., Susin, S. A., Marchetti, P., Hirsch, T., GomezMonterrey, I., Castedo, M., and Kroemer, G. (1996) Mitochondrial control of nuclear apoptosis. J . Exp. Med. 183, 1533-1544.

(39) Stridh, H., Orrenius, S., and Hampton, M. B. (1999) Caspase involvement in the induction of apoptosis by the environmental toxicants tributyltin and triphenyltin. Toxicol. Appl. Pharmacol. 156, 141-146.

(40) Woo, M., Hakem, R., Soengas, M. S., Duncan, G. S., Shahinian, A., Kägi, D., Hakem, A., McCurrach, M., Khoo, W., Kaufman, S. A., Senaldi, G., Howard, T., Lowe, S. W., and Mak, T. W. (1998) Essential contribution of caspase3/CPP32 to apoptosis and its associated nuclear changes. Genes Dev. 12, 806-819.

(41) Hartley, A., Stone, J . M., Heron, C., Cooper, J . M., and Schapira, A. H. V. (1994) Complex I Inhibitors induce dose-dependent apoptosis in PC12 cells: relevance to Parkinson's disease. J . Neurochem. 63, 1987-1990.

(42) Bonfoco, E., Krainc, D., Ankarcrona, M., Nicotera, P., and Lipton, S. A. (1995) Apoptosis and necrosis: two distinct events induced respectively by mild and intense insults with NMDA or nitric oxide/superoxide in cortical cell cultures. Proc. Natl. Acad. Sci. U.S.A. 92, 12162-12166.

(43) Ferrari, D., Stepczynska, A., Los, M., Wessel borg, S., and Schulze Osthoff, K. (1998) Differential regulation and ATP requirement for caspase-8 and caspase-3 activation during CD95- and anticancer drug-induced apoptosis. J. Exp. Med. 188, 979-984.

(44) Li, P., Nijhawan, D., Budihardjo, I., Srinivasula, S. M., Ahmad, M., Alnemri, E. S., and Wang, X. (1997) Cytochrome c and dATPdependent formation of Apaf-1/Caspase-9 complex initiates an apoptotic protease cascade. Cell 91, 479-489.

(45) Reader, S., Moutardier, V., and Denizeau, F. (1999) Tributyltin triggers apoptosis in trout hepatocytes: the role of $\mathrm{Ca}^{2+}{ }^{2+}$, protein kinase $C$ and proteases. Biochim. Biophys. Acta 1448, 473-485.

(46) Skilleter, D. N. (1975) The decrease of mitochondrial substrate uptake caused by trialkyltin and trialkyl-lead compounds in chloride media and its relevance to inhibition of oxidative phosphorylation. Biochem. J . 146, 465-471.
(47) Cain, K., Partis, M. D., and Griffiths, D. (1977) Studies of energylinked reactions. Localisation of the site of action of trialkyltin in yeast mitochondria. Biochem. J . 162, 575-580.

(48) Hampton, M. B., and Orrenius, S. (1998) Redox regulation of apoptotic cell death. Bi ofactors 8, 1-5.

(49) Nobel, C. S., Burgess, D. H., Zhivotovsky, B., Burkitt, M. J ., Orrenius, S., and Slater, A. F. (1997) Mechanism of dithiocarbamate inhibition of apoptosis: thiol oxidation by dithiocarbamate disulfides directly inhibits processing of the caspase- 3 proenzyme. Chem. Res. Toxicol. 10, 636-643.

(50) Hampton, M. B., Zhivotovsky, B., Slater, A. F. G., Burgess, D. H., and Orrenius, S. (1998) Importance of the redox state of cytochrome c during caspase activation in cytosolic extracts. Biochem. J . 329, 95-99.

(51) Stridh, H., Orrenius, S., and Hampton, M. B. (1999) Caspase involvement in the induction of apoptosis by the environmental toxicants tributyltin and triphenyltin. Toxicol. Appl. Pharmacol. (in press).

(52) Lenartowicz, E., Bernardi, P., and Azzone, G. F. (1991) Phenylarsine oxide induces the cyclosporin A-sensitive membrane permeability transition in rat liver mitochondria. J. Bioenerg. Biomembr. 23, 679-688.

(53) Zamzami, N., Susin, S. A., Marchetti, P., Hirsch, T., GómezMonterrey, L ., Castedo, M., and Kroemer, G. (1996) Mitochondrial control of nuclear apoptosis. J . Exp. Med. 183, 1533-1544.

(54) Marzo, I., Brenner, C., Zamzami, N., J ürgensmeier, J . M., Susin S. A., Vieira, H. L. A., Prévost, M.-C., Xie, Z., Matsuyama, S., Reed, J . C., and Kroemer, G. (1998) Bax and adenine nucleotide translocator cooperate in the mitochondrial control of apoptosis. Science 281, 2027-2031.

(55) Vander Heiden, M. G., Chandel, N. S., Schumacker, P. T., and Thompson, C. B. (1999) BCl-xL prevents cell death following growth factor withdrawal by facilitating mitochondrial ATP/ADP exchange. Mol. Cell 3, 159-167.

(56) Susin, S. A., Lorenzo, H. K., Zamzami, N., Marzo, I., Snow, B. E., Brothers, G. M., Mangion, J., J acotot, E., Constantini, P., Loeffler, M., Larochette, N., Goodlett, D. R., Aebersold, R. Siderovski, D. P., Penninger, J. M., and Kroemer, G. (1999) Molecular characterization of mitochondrial apoptosis-inducing factor. Nature 397, 441-446.

(57) Schierle, G. S., Leist, M., Martinou, J.-C., Widner, H., Nicotera, P., and Brundin, P. (1999) Differential effects of Bcl-2 overexpression on fiber outgrowth and survival of embryonic dopaminergic neurons in intracerebral transplants. Eur. J . Neurosci. 11 3073-3081.

\section{TX990041C}

